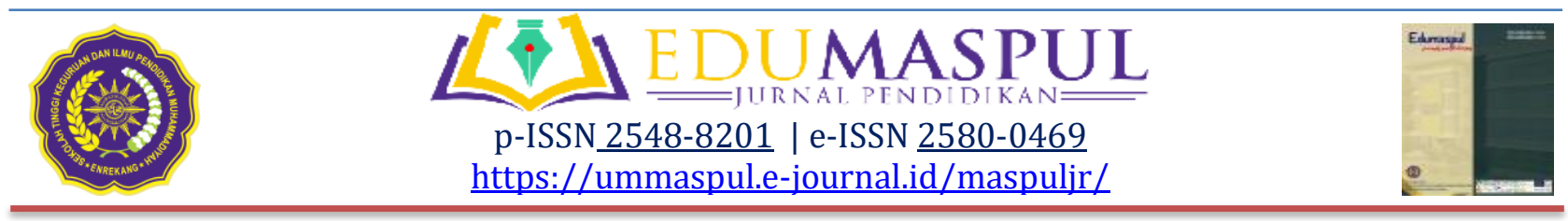

\title{
Pembelajaran Permaian Kinestetik Gobak Sodor untuk Siswa Sekolah Dasar
}

\author{
Frendi Aru Fantiro1, Bustanol Arifin² \\ 1-2Pendidikan Guru Sekolah Dasar, Universitas Muhammadiyah Malang, Indonesia \\ $\bowtie$ Corresponding email: 1frendy_aru@umm.ac.id; 2barifin@umm.ac.id
}

\begin{abstract}
Receive: 25-09-2019
Accepted: 02-10-2019

Published: 06-10-2019

Abstrak. Pendidikan merupakan sebuah wadah atau institusi formal yang bertujuan untuk mendidik anak dari yang tidak bisa menjadi bisa, dari yang belum baik menjadi baik. Proses pembelajaran agar peserta didik secara aktif mengembangkan potensi dirinya untuk memiliki kekuatan spiritual, keagamaan, pengendalian diri, kepribadian kecerdasan, akhlak mulia, serta keterampilan yang dibutuhkan oleh dirinya dan orang orang sekitar. Berikut adalah langkah-Langkah Penelitia: (1) Penelitian dan pengumpulan data (research and information collecting). (2) Perencanaan (planning). (3) Pengembangan draft produk (develop preliminary form of product). (4) Uji coba lapangan awal (preliminary field testing). (5) Merevisi hasil uji coba (main product revition). (6) Uji coba lapangan (main field testing (7) Penyempurnaan produk hasil uji lapangan (operational product revision). (8) Uji pelaksanaan lapangan (operational field testing (9) Penyempurnaan produk akhir (final product revision). (10) Diseminasi dan implementasi (dissemination and implementation). Dari 37 responden hanya 1 siswa $(2,70 \%)$ yang menjawab tidak mudah pada aspek tingkat kerumitan soal dalam permaian gobag sodor. Selanjutnya, 1 siswa $(2,70 \%)$ yang menjawab cukup menarik model permainan gobag sodor, cukup paham terhadap konsep materi yang disampaikan melalui model permainan gobag sodor, cukup jelas gambar dan tulisan dalam media permainan gobag sodor, dan cukup jelas soal yang digunakan dalam media permainan gobag sodor.
\end{abstract}

Kata Kunci: Permainan Kinestetik; Gobak Sodor; Siswa Sekolah Dasar.

\begin{abstract}
Education is a formal institution or institution that aims to educate children from those who cannot be able to, from those who are not good to become good. The learning process so that students actively develop their potential to have spiritual, religious, self-control, intelligence personality, noble character, and the skills needed by themselves and those around them. The following are the Research Steps: (1) Research and data collection (research and information collecting). (2) Planning (planning). (3) Development of product draft (develop preliminary form of product). (4) Preliminary field testing. (5) Revising the results of the trial (main product revition). (6) Main field testing (7) Refinement of operational product revision products (8) Operational field testing (9) Refinement of final product (final product revision). (10) Dissemination and implementation (dissemination and implementation). Of 37 respondents only 1 student (2.70\%) answered that it was not easy on the aspect of the complexity of the questions in the Sodor Gobag. Next, 1 student (2.70\%) answered quite interesting game models Gobag Sodor, quite understand the concept of the material delivered through the Sodor Gobag game model, quite clear pictures and writings in the Gobag Sodor game media, and quite clear about the questions used in the Sodor Gobag media.
\end{abstract}

Keywords: Kinesthetic Game; Gobak Sodor; Student of Elementary School 


\section{PENDAHULUAN}

Pendidikan merupakan sebuah wadah atau institusi formal yang bertujuan untuk mendidik anak dari yang tidak bisa menjadi bisa, dari yang belum baik menjadi baik. Proses pembelajaran agar peserta didik secara aktif mengembangkan potensi dirinya untuk memiliki kekuatan spiritual, keagamaan, pengendalian diri, kepribadian kecerdasan, akhlak mulia, serta keterampilan yang dibutuhkan oleh dirinya dan orang orang sekitar. Semakin pesat perkembangan zaman membuat tuntutan manusia terhadap kreatifitas mengembangkan dan berinovasi dalam melakukan pembelajaran juga ikut meningkat. Sehingga diharapkan dengan melakukan pembelajaran yang kreatif dan inovatif dapat merangsang anak untuk belajar.

Setiap anak memiliki kekurangan dan kelebihan masing-masing, begitu pula dengan tingkat kecerdasan dan cara belajar yang beda-beda. Pada umumnya cara belajar anak dengan melalui sebuah permainan, karna dengan melakukan permainan anak mampu memaksimalkan kemampuannya dari beberapa aspek, diantaranya bahasa, social, kognitif, fisik dan moralnya (Diana Mutiah, 2010). Apa yang dilakukan anak-anak pada saat di Sekolah Dasar memiliki dampak terhadap kehidupan anak selanjutnya. Apa yang dilakukan anak-anak pada saat di Sekolah Dasar akan memiliki daya ingat yang cukup lama, bahkan tidak dapat terhapuskan, bila suatu saat ada sebuah kejadian yang memicu pengalaman hidup di masa lalu maka aka ada dampak tersebut akan muncul kembali meski dalam bentuk yang berbeda.

Individu anak di usia sekolah dasar adalah individu yang sedang mengalami proses pertumbuhan dan perkembangan yang sangat pesat. Bahkan dianggap sebagai sebuah lompatan perkembangan maka dari itu usia sekolah dasar dikatakan sebagai gold age (usia emas). Kecerdasan kinestetik, yakni kemampuan untuk menggunakan semua anggota badannya untuk mengekspresikan ide-ide dan perasaan atau menggunakan tangan untuk menghasilkan dan mentransformasikan sesuatu. Kecerdasan ini mencakup keahlian keahlian fisik khusus seperti koordinasi, keseimbangan, ketangkasan, kekuatan, kelentukan dan kecepatan. (Howard Gardner 2001:3).

Kecerdasan kinestetik adalah kemampuan menyelaraskan pikiran dengan badan sehinnga apa yang dikatakan oleh pikiran akan tertuang dalam bentuk gerakan-gerakan badan yang indah, kreatif, dan mempunyai makna. Definisi ini merujuk pada tulisan yang mengatakan bahwa "...Sebuah keselarasan antara pikiran dan tubuh, dimana pikiran dilatih untuk memanfaatkan tubuh sebagaimana mestinya dan tubuh dilatih untuk dapat merespon ekspresi kekuatan dari pikiran" (Linda C, Bruce C dan Dee D, 2002).

Anak-anak yang memiliki kecerdasan kinestetik memiliki model belajar yang memiliki kemampuan di anggota badan, seperti tangan atau tubuhnya hal in bisa disebut belajar dengan cara kinestetik. Mereka merespon sesuatu dengan baik pada komunikasi nonverbal. Mereka juga cepat belajar gesture, yakni menyampaikan sesuatu dengan bagian tubuhnya, terutama tangan. Kecerdasan kinestetik berhubungan erat dengan motorik. Motorik merupakan perkembangn pengendalian gerakan tubuh melalui kegiatan yang terkoordinir antara susunan saraf, otot, otak, dan spinal cord.

Pembelajaran yang dilakukan di Sekolah Dasar ataupun di Madrasah Ibtidaiah khususnya pendidikan jasmani 
sebagian besar dikemas dalam bentuk permainan (game). Siswa tidak diarahkan untuk menguasai cabang-cabang olahraga permainan tertentu, namun lebih mengutamakan proses perkembangan motorik (tim penyusun kurikulum berbasis kompetensi 2003:8). Sehingga sangat perlu bagi seorang guru Pendidikan Jasmani inovasi dan pengembangan untuk menciptakan permainan bagi anak.

Berdasarkan analisis kebutuhan yang dilakukan SD Negeri Klojen Kota Malang diperlukannya yang berbasis kemampuan kinestetik yang dikembangkan sesuai dengan kebutuhan anak khususnya anak Sekolah Dasar. Oleh karena itu perlu pengembangan permainan kinestetik untuk anak sekolah dasar untuk menunjang kemampuan gerak siswa, sehingga guru pendidikan jasmani dapat memodifikasi permainan sederhana yang di harapkan tercipta pembelajaran yang efektif, inovatif, kreatif dan mandiri.

\section{METHOD}

Penelitian pengembangan ini akan dilaksanakan di SDN Klojen 1. Jl Patimura no 1. Model pengembangan yang digunakan dalam penelitian ini mengacu pada model pengembangan (research and development) dari Borg dan Gall (1983: 475) berikut adalah langkah-Langkah Penelitia : (1) Penelitian dan pengumpulan data (research and information collecting). Pengukuran kebutuhan, studi literatur, penelitian dalam skala kecil, dan pertimbangan-pertimbangan dari segi nilai. (2) Perencanaan (planning). Menyusun rencana penelitian, meliputi kemampuan-kemampuan yang diperlukan dalam pelaksanaan penelitian, rumusan tujuan yang hendak dicapai dengan penelitian tersebut, desain atau langkahlangkah penelitian, kemungkinan pengujian dalam lingkup terbatas. (3)
Pengembangan draft produk (develop preliminary form of product). Pengembangan bahan pembelajaran, proses pembelajaran dan instrumen evaluasi. (4) Uji coba lapangan awal (preliminary field testing). Uji coba di lapangan pada subyek uji coba (guru). Selama uji coba diadakan pengamatan, wawancara dan pengedaran angket. (5) Merevisi hasil uji coba (main product revition). Memperbaiki atau menyempurnakan hasil uji coba. (6) Uji coba lapangan (main field testing). Melakukan uji coba yang lebih luas pada orang subyek uji coba. Data kuantitatif penampilan guru sebelum dan sesudah menggunakan model yang dicobakan dikumpulkan. Hasil-hasil pengumpulan data dievaluasi dan kalau mungkin dibandingkan dengan kelompok pembanding. (7) Penyempurnaan produk hasil uji lapangan (operational product revision). Menyempurnakan produk hasil uji lapangan. (8) Uji pelaksanaan lapangan (operational field testing). Dilaksanakan pada 10 sampai dengan 30 sekolah melibatkan 40 sampai dengan 200 subyek. Pengujian dilakukan melalui angket, wawancara, dan observasi dan analisis data. (9) Penyempurnaan produk akhir (final product revision). Penyempurnaan didasarkan masukan dari uji pelaksanaan lapangan. (10) Diseminasi dan implementasi (dissemination and implementation). Melaporkan hasilnya dalam pertemuan profesional dan dalam jurnal. Bekerjasama dengan penerbit untuk penerbitan. Memonitor penyebaran untuk mengontrol kualitas.

Tabel 1. Tahap dan Langkah Penelitian Pengembangan

\begin{tabular}{|l|c|ll|}
\hline \multicolumn{1}{|c|}{ Tahap } & Langkah & \multicolumn{2}{|c|}{ Aktivitas } \\
\hline $\begin{array}{l}\text { Pra } \\
\text { Pengembangan }\end{array}$ & 1 & 1. $\begin{array}{l}\text { Pengumpulan data } \\
\text { awal } \\
\end{array}$ & $\begin{array}{l}\text { 2. Penyusunan proposal } \\
\text { penelitian }\end{array}$ \\
\hline
\end{tabular}




\begin{tabular}{|c|c|c|}
\hline Tahap & Langkah & Aktivitas \\
\hline & 2 & $\begin{array}{l}\text { 3. analisa kebutuhan } \\
\text { Perencanaan produk }\end{array}$ \\
\hline Pengembangan & 3 & $\begin{array}{l}\text { Produksi Produk berupa } \\
\text { Buku Panduan Permainan } \\
\text { Motorik } \\
\text { Evaluasi Formatif, } \\
\text { Uji coba awal (1) } \\
\text { Evaluasi satu-satu dengan } \\
\text { para ahli yang memadai } \\
\text { dalam kontek: materi, } \\
\text { teknologi dan desain } \\
\text { pembelajaran motorik dan } \\
\text { penjas pasan } \\
\text { Perbaikan awal (1) } \\
\text { Uji coba awal (2) } \\
\text { Evaluasi pakar (Expert } \\
\text { Judgement) dengan pakar } \\
\text { materi, pakar teknologi, } \\
\text { pakar pendidikan dasar, } \\
\text { serta pakar desain } \\
\text { pembelajaran motorik dan } \\
\text { penjas } \\
\text { Perbaikan awal (2) }\end{array}$ \\
\hline Penerapan & $\begin{array}{c}9 \\
10 \\
\end{array}$ & $\begin{array}{l}\text { Uji coba lapangan (1) } \\
\text { Evaluasi skala terbatas } \\
\text { Perbaikan operasional (1) } \\
\text { Uji coba lapangan (2) } \\
\text { Evaluasi dengan skala } \\
\text { terbatas Perbaikan } \\
\text { operasional (2) } \\
\text { Penerapan } \\
\text { Deseminasi }\end{array}$ \\
\hline
\end{tabular}

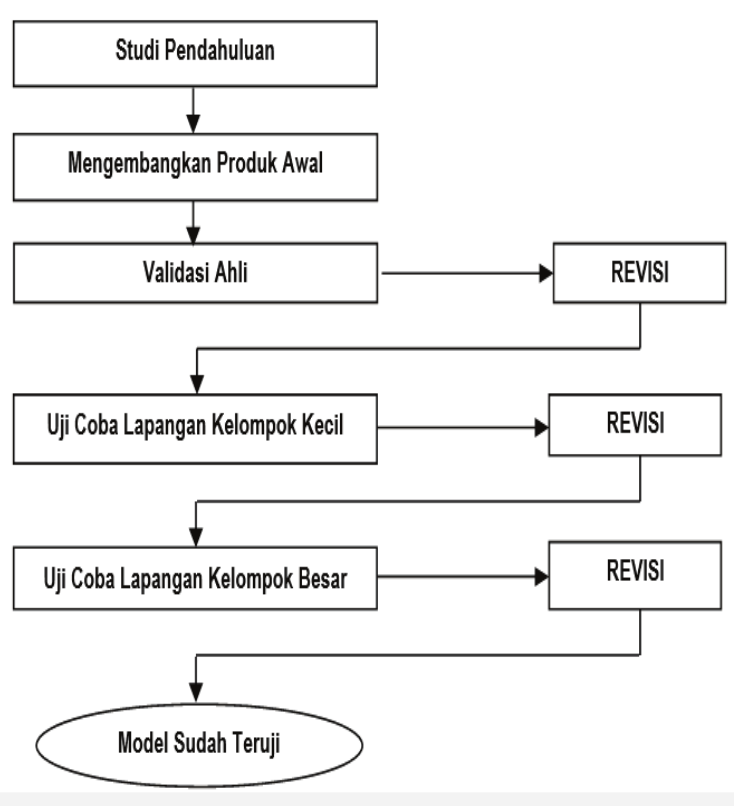

Gambar 1. Prosedur Penelitian dan Pengembangan

\section{HASIL DAN PEMBAHASAN}

Produk pengembangan yang akan diujicobakan ialah model perkembangan dari permainan Gobak sodor yang pernah dikebangkan oleh Muhyi pada tahun 2012, permainan ini merupakan permainan yang ditujukan untuk merangsang kecerdasan kinestetik pada anak, yang nantinya akan digunakan di sekolah untuk proses belajar mengajar pada guru yang nanti akan tertuang pada Rencana Pelaksanaan Pembelajaran (RPP). Model permainan ini mengacu pada buku yang telah divalidasi oleh ahli desain model pembelajaran dan ahli materi pembelajaran PENJAS. Dari bebrapa peilaian para ahli yang telah di validasi, selanjutnya dilakukan beberapa kali revisi hikngga akhirnya dapat disetujui oleh validator ahli sebelum diuji cobakan di lapangan, berikut merupakan langkahlangkah permainan yang sudah dikembangkan.

\section{Permainan Gobak Sodor}

Permainan Gobak sodor di contohkan pada Gambar 2.

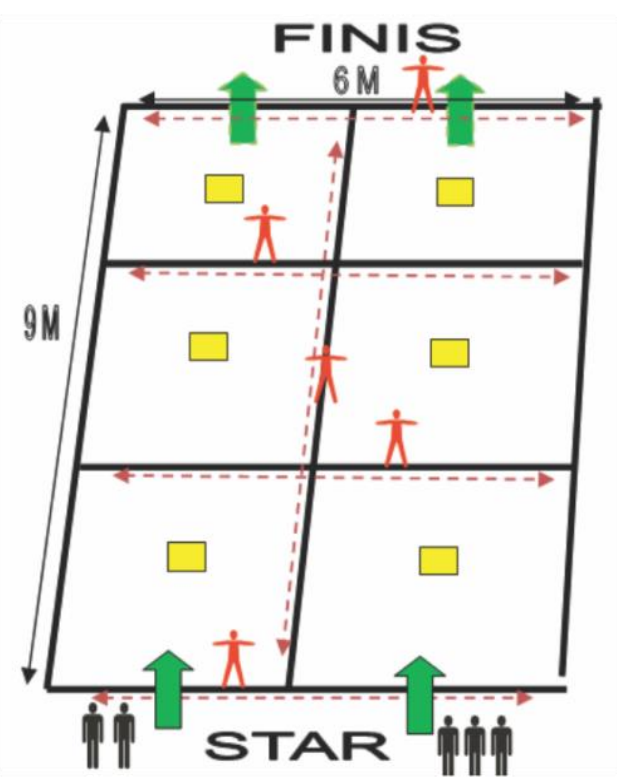

Gambar 4. Lapangan Permainan Gobak Sodor 
Keterangan:

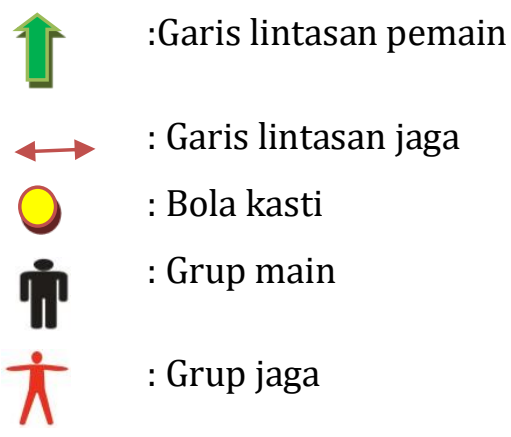

Berikut ini uraian deskripsi dari permainan gobak sodor yang telah dikembangkan.

a. Sebelum bermain perlu membuat garis-garis penjagaan dengan kapur atau dengan alat lain agar terlihat garis-garis penjagaannya, kemudian dibagi menjadi enam bagian dan diberi garis tengah yang memotong garis-garis tersebut.

b. Membagi para peserta menjadi dua kelompok, satu kelompok terdiri atas 3-5 atau dapat disesuaikan dengan jumlah peserta. Satu kelompok akan menjadi kelompok jaga dan kelompok lain akan menjadi lawan. Penentuan kelompok jaga dan kelompok lawan biasanya dilakukan dengan suten oleh perwakilan dari masing-masing kelompok.

c. Kelompok yang mendapat giliran jaga akan menjaga lapangan, caranya yang dijaga adalah garis horizontal dan ada juga yang menjaga garis batas vertical. Penjaga garis horisontal tugasnya adalah berusaha untuk menghalangi lawan mereka yang juga berusaha untuk melewati garis batas yang sudah ditentukan. Pemain yang menjaga garis horizontal, sepanjang garis horizontal yang dijaga bisa bergerak ke kanan dan ke kiri. Bagi yang bertugas untuk menjaga garis vertikal, maka tugasnya adalah mennjaga keseluruhan garis batas vertikal yang terletak di tengah lapangan.

d. Sedangkan tim yang menjadi lawan, harus berusaha melewati baris ke baris hingga baris paling belakang, kemudian kembali lagi melewati penjagaan lawan hingga sampai ke baris awal tanpa tersentuh oleh tim jaga

e. Bola harus menyentuh kotak kuning ditengan disetiap kotak, jadi ketika orangnya belum finis tapi orangnya sudah maka belum dihitung skor, skor akan dihitung jikabola telah menyentuh kotak kuning ditengah dari awal hingga ke baris paling belakang, dan kembali ke depan.

\section{Uji Coba Lapangan Kelompok Kecil}

Hasil tanggapan siswa terhadap model permainan traisional gobak sodor pada uji coba kelompok kecil secara umum mendapat respon yang positif, yakni 93,40\% menjawab sangat menarik. Hal tersebut dikarenakan adanya tambahan bola yang harus dipertahankan dari kejaran lawan. gobag sodor menurut siswa, $85,72 \%$ menjawab sangat mudah, sedangkan 14,28\% menjawab mudah.

Terakhir tanggapan siswa terhadap teknik permainan dan gobag sodor, $83,33 \%$ siswa menjawab sangat mudah dimainkan. Hasil jawaban/respons siswa terhadap masing-masing aspek penilaian model permainan dan gobag sodor. Secara keseluruhan gambaran jawaban siswa terhadap model permainan gobak sodor.

Tabel 2. Respons Siswa terhadap Model Permainan Gobak sodor pada Uji Coba Kelompok Kecil 


\begin{tabular}{llr}
\hline No & $\begin{array}{l}\text { Kriteria } \\
\text { Respons/Jawaban Siswa }\end{array}$ & \multicolumn{1}{c}{$\begin{array}{l}\text { Gobak } \\
\text { Sodor }\end{array}$} \\
\hline 1 & $\begin{array}{l}\text { Sangat menarik, sangat } \\
\text { jelas, dan sangat mudah }\end{array}$ & $84,12 \%$ \\
2 & $\begin{array}{l}\text { Menarik jelas dan } \\
\text { mudah }\end{array}$ & $15,88 \%$ \\
3 & $\begin{array}{l}\text { Cukup menarik, cukup } \\
\text { jelas dan cukup mudah }\end{array}$ & $0 \%$ \\
4 & $\begin{array}{l}\text { Tidak menarik, tidak } \\
\text { jelas, dan tidak mudak }\end{array}$ & $0 \%$ \\
\hline
\end{tabular}

\section{Uji Coba Lapangan Kelompok Besar}

Setelah uji coba kelompok kecil, selanjutnya dilakukan uji coba lapangan kelompok besar, hal ini bertujuan untuk menemukan model permainan gobag sodor sebagai suatu model pembelajaran yang standar dan dapat diimplementasikan pada setiap kelas dengan kategori berbeda. Prosedur uji coba kelompok besar pada dasarnya sama dengan uji coba kelompok kecil, di samping dilakukan uji coba pembelajaran menggunakan model permainan gobag sodor, juga dilakukan analisis respon siswa terhadap model tersebut.

\section{Tanggapan Siswa terhadap Model Permainan Tradisional Gobak Sodor}

Aspek tanggapan siswa terhadap penggunaan model permainan gobak sodor siswa antusisas pada ssat melakukan permainan gobak sodor. Hal ini terlihat dari hasil jawaban angketyang dibagikan kepada siswa setelah melakukan permainan gobak sodor. Dari 37 responden hanya 1 siswa $(2,70 \%)$ yang menjawab tidak mudah pada aspek tingkat kerumitan soal dalam permaian gobag sodor. Selanjutnya, 1 siswa $(2,70 \%)$ yang menjawab cukup menarik model permainan gobag sodor, cukup paham terhadap konsep materi yang disampaikan melalui model permainan gobag sodor, cukup jelas gambar dan tulisan dalam media permainan gobag sodor, dan cukup jelas soal yang digunakan dalam media permainan gobag sodor. Bila dipersentasekan respon/jawaban siswa secara keseluruhan dari masing-masing aspek penilaian terhadap model permainan gobag sodor dapat dilihat pada Tabel 3.

Tabel 3. Respons Siswa terhadap Model Permainan Gobak sodor

\begin{tabular}{llr}
\hline No & Kriteria Respons/Jawaban & $\begin{array}{l}\text { Gobak } \\
\text { Sodor }\end{array}$ \\
\hline 1 & Siswa & Sangat menarik, sangat \\
& jelas, dan sangat mudah & \\
2 & Menarik jelas dan mudah & $31,09 \%$ \\
3 & $\begin{array}{l}\text { Cukup menarik, cukup } \\
\text { jelas dan cukup mudah }\end{array}$ & $1,80 \%$ \\
4 & Tidak menarik, tidak jelas, & $0,45 \%$ \\
& dan tidak mudak & \\
\hline
\end{tabular}

Beberapa kesimpulan hasil penelitian terdahulu menunjukkan minimnya guru dalam menciptakan bahan ajar berupa model pembelajaran yang berbasis budaya lokal, yakni permainan tradisional.

Pelestarian eksistensi permainan tradisional dan pengkajian yang lebih mendalam tentang manfaat yang dapat diperoleh melalui permainan tradisional, baik secara kognitif, psikologis, maupun sosial. Mengingat begitu pentingnya nilai budaya sebagai sumber belajar, maka seharusnya hal ini ditindaklanjuti dengan membuat model pembelajaran berbasis budaya lokal yang di antaranya adalah permainan tradisional anak. Model pembelajaran ini sangat penting dikembangkan untuk menjadikan pembelajaran lebih bermanfaat bagi siswa. Effendi (2011) berpendapat bahwa nilai budaya lokal khususnya kearifan lingkungan sangat penting untuk menjadikan pembelajaran semakin 
bermakna. Senada dengan Efendi (2011) menyatakan bahwa model pembelajaran terpadu berbasis budaya yang dikembangkannya terbukti secara signifikan lebih efektif meningkatkan apresiasi siswa terhadap budaya lokal simultan dengan penguasaan materi pelajaran bila dibandingkan dengan model pembelajaran yang selama ini digunakan guru.

Permainan tradisional merupakan salah satu bentuk permainan yang mengandung banyak nilai universal dan nilai-nilai kearifan lokal (Gunawan,2016). Kearifan lokal merupakan gagasan konseptual yang hidup dalam masyarakat, tumbuh dan berkembang secara terus-menerus dalam kesadaran masyarakat dari yang sifatnya berkaitan dengan kehidupan yang sakral sampai dengan yang profane (Gunawan, 2012). Kreativitas anak akan berkembang ketika guru menerapkan pembelajaran berbasis kearifan lokal (Gunawan, dkk., 2014). Nilai-nilai budaya lokal menjadi sumber belajar yang efektif dalam mengembangkan pembelajaran agar para siswa dekat dengan lingkungan dan budaya yang berkembang di masyarakat setempat (Gunawan dan Sulistyoningrum, 2013). Kepala sekolah memiliki peran yang strategis dalam membina guru agar dapat mengembangkan pembelajaran yang mampu mewariskan budaya lokal (Gunawan, 2015).

\section{KESIMPULAN}

Kelebihan dari model permainan tradisional gobag sodor untuk merangsang kecerdasan kinestetik sangat baik, selain itu untuk menumbuh kembang- kan unsurunsur pendidikan yang telah disebutkan diatas, juga agar siswa lebih meningkatkan apre- siasinya terhadap permainan tradisional, Tujuan ini jelas seirama dengan hakikat tujuan pembelajaran yang sesungguhnya, yaitu terciptanya warga negara yang berbudi pekerti luhur mempunyai jiwa sosial yang tinggi. Oleh karena itu, model permainan tradisional gobag sodor dikembangkan ini sesuai dengan kebutuhan perkembangan kognitif, psikomotorik dan afektif siswa, seraya memanfaatkan sumber belajar yang berbasis kearifan lokal.

\section{Daftar Pustaka}

[1] Brog, W. R., dan Gall, M. D. 1983. Educational Research: An Introduction. London: Longman, Inc.

[2] Effendi, A. 2011. Implementasi Kearifan Lingkungan dalam Budaya Masyarakat Adat Kampung Kuta sebagai Sumber Pembelajaran IPS: Studi Etnografi pada Masyarakat Adat Kampung Kuta dan Kajian PTK di SMP Negeri 1 Tambaksari Kabupaten Ciamis. Tesis tidak diterbitkan. Bandung: Universitas Pendidikan Indonesia.

[3] Gardner, Howard. 1983. Frances of Mind : The Theory of Multiple Intelligence. New York: Basic Book

[4] Gunawan, I. 2012. Mengembangkan Karakter Bangsa Berdasarkan Kearifan Lokal. Prosiding Seminar Nasional Meretas Sekolah Humanis untuk Mendesain Siswa Sekolah Dasar yang Cerdas dan Berkarakter, Fakultas Keguruan dan Ilmu Pendidikan Universitas Muhammadiyah Surakarta, 6 Mei, hlm. 67 s.d. 79.

[5] Gunawan, I. 2015. Pengaruh Kepemimpinan Transformasional dan Kepuasan Kerja terhadap Perilaku.

[6] Mutiah, Diana. 2010. Psikologi Bermain Anak Usia Dini. Jakarta: Kencana.

[7] Ibrahim dan Nana Syaodih Sukmadinata. 2010. Perencanaan Pengajaran. Jakarta: Rineka Cipta

[8] Linda C, Bruce C dan Dee D. 2002. Multiple Intelligences: Metode Terbaru Melestarikan Kecerdasan. Jakarta: Inisiasi Press. 